\title{
latrogenic hyponatremia in a patient with bipolar disorder
}

\author{
Geetha Dhatreecharan, MD, FAPA
}

Dr. Dhatreecharan is Assistant Professor, Department of Psychiatry, University of Cincinnati, Cincinnati, Ohio.

\section{Disclosure}

The author reports no financial relationships with any companies whose products are mentioned in this article, or with manufacturers of competing products.

doi: 10.12788/cp.0191

\section{f}

Discuss this article at www.facebook.com/ MDedgePsychiatry $\mathbf{0}$
Editor's note: Readers' Forum is a department for correspondence from readers that is not in response to articles published in CURRENT PSYCHIATRY. All submissions to Readers' Forum undergo peer review and are subject to editing for length and style. For more information,contactletters@currentpsychiatry.com.

B ipolar disorder is a chronic mental disorder, often with onset at a young age. An estimated $4.4 \%$ of US adults experience bipolar disorder at some time in their lives. ${ }^{1}$ According to the National Comorbidity Survey Replication, the past-year prevalence of bipolar disorder in adults age $\geq 60$ is $0.7 \%{ }^{1}$ An estimated $83 \%$ of people with bipolar disorder have serious impairment, which is the highest percentage of serious impairment among mood disorders. ${ }^{1}$ Bipolar I disorder affects men and women equally, whereas bipolar II disorder seems to occur more frequently in women. ${ }^{2}$ Symptoms of bipolar disorder include episodes of mania, depression, and mixed states. ${ }^{2}$

A variety of medications-including mood stabilizers, lithium, and antipsychotics (Table 1, ${ }^{3,4}$ page e5 and Table 2, ${ }^{4}$ page e5) - and somatic treatments such as electroconvulsive therapy and transcranial magnetic stimulation are used to manage the depressive and manic/mixed episodes of bipolar disorder. Treatment should be individualized based on the patient's symptom severity, sensitivity, response to treatment, and preferences.

The most common reason for discontinuing a medication is intolerance to adverse effects. Some adverse effects are mild and may lessen over time. Others can be lifethreatening. Thus, medications should be chosen carefully and started at low doses, and patients should be closely monitored for adverse effects at regular intervals.

Here I describe the case of a patient with bipolar disorder who developed hyponatremia while being treated with the secondgeneration antipsychotic lurasidone.

\section{CASE REPORT}

Mrs. G, age 65, lives with her husband. She has a history of bipolar disorder, chronic kidney disease, diabetes mellitus type 2 , obstructive sleep apnea, hypertension associated with hyperaldosteronism, and obesity, for which she has undergone bariatric surgery. Symptoms of bipolar disorder started when she was in her 30s, following the death of her father. Her initial symptoms included depressed mood, anger, irritability, difficulty sleeping, racing thoughts, and impulsive spending. She did not have any suicidal ideation or homicidal ideation. She did not have anxiety, posttraumatic stress disorder, or obsessive-compulsive disorder symptoms. She was diagnosed with bipolar disorder. For some time, she took perphenazine, $16 \mathrm{mg} / \mathrm{d}$, divalproex sodium, 1,500 mg/d, and temazepam, $30 \mathrm{mg} / \mathrm{d}$ at bedtime. These doses were reduced as her mood stabilized. Over time, divalproex sodium was tapered and discontinued, and perphenazine was reduced to $4 \mathrm{mg} / \mathrm{d}$ at bedtime. Lithium was tried briefly but discontinued because Mrs. G did not tolerate it well. She has never been hospitalized for mental health issues, but did have one emergency department visit a very long time ago. She has no his- 
tory of suicide attempts, and there is no family history of completed suicide. There is a family history of bipolar disorder in her mother.

Mrs. $\mathrm{G}$ was born and raised outside the United States in a stable, two-parent home. She had no maltreatment during childhood. She has a bachelor's degree and was employed. She is a social drinker, with no history of treatment for alcohol use disorder.

Mrs. $G$ was stable on perphenazine, $4 \mathrm{mg} / \mathrm{d}$, and temazepam, $30 \mathrm{mg} / \mathrm{d}$, until 5 years ago. In 2016, she became concerned about her weight and overall health, and underwent bariatric surgery (gastric sleeve). After this surgery, Mrs. G experienced changes in mood and thought. She felt paranoid and had ideas of reference, social sensitivity, increased irritability, and poor self-esteem. Perphenazine was discontinued, divalproex was reintroduced, and lurasidone was started. Lurasidone was titrated up to $120 \mathrm{mg} / \mathrm{d}$, and divalproex up to $1,500 \mathrm{mg} / \mathrm{d}$. Temazepam, $30 \mathrm{mg} / \mathrm{d}$ at bedtime, was continued for her insomnia. She also occasionally took over-the-counter melatonin, 5 to $10 \mathrm{mg}$, as needed for insomnia.

Mrs. G improved on this combination, and became stable and euthymic in September 2017. Other than a brief hypomanic episode in Spring 2018 that resolved quickly, she remained euthymic. During routine followup visits, Mrs. G's nephrologist noticed that her sodium levels had been fluctuating. Mrs. $G$ said her nephrologist was not sure exactly what was causing these fluctuations, and she continued to take the same medications.

In June 2018, Mrs. G developed tremors, slowing, and lethargy. Lurasidone was gradually reduced to $60 \mathrm{mg} / \mathrm{d}$ and divalproex to $750 \mathrm{mg} / \mathrm{d}$. Temazepam, $30 \mathrm{mg} / \mathrm{d}$ at bedtime, was continued. In July 2018, divalproex was further reduced to $500 \mathrm{mg} / \mathrm{d}$ because Mrs. G's free valproic acid levels were elevated. In February 2019, lurasidone was further reduced to $40 \mathrm{mg} / \mathrm{d}$ due to blunted affect, and in April 2019, escitalopram, $10 \mathrm{mg} / \mathrm{d}$, was added for symptoms of depression (off-label), and anxiety. In June 2019, Mrs. G's sodium level was $127 \mathrm{mEq} / \mathrm{L}$ (reference range: 135 to

\section{Table 1}

\section{Second-generation antipsychotics for bipolar depression in adults ${ }^{3,4}$}

\begin{tabular}{l:l} 
Medication & Dosage \\
\hline Olanzapine/fluoxetine & $6 / 25$ to $12 / 50 \mathrm{mg} / \mathrm{d}$ \\
\hline Cariprazine & 1.5 to $3 \mathrm{mg} / \mathrm{d}$ \\
\hline Quetiapine & 300 to $600 \mathrm{mg} / \mathrm{d}$ \\
\hline Quetiapine XR & $300 \mathrm{mg} / \mathrm{d}$ at bedtime \\
\hline Lurasidone & 20 to $120 \mathrm{mg} / \mathrm{d}$ \\
\hline & \\
\hline Table 2 & \\
\hline Second-generation \\
antipsychotics for bipolar \\
mania/mixed episode ${ }^{4}$ \\
\hline Medication & Dosage \\
\hline Cariprazine & 3 to 6 mg/d \\
\hline Aripiprazole & 15 to $30 \mathrm{mg} / \mathrm{d}$ \\
\hline Asenapine & 5 to $10 \mathrm{mg}$ sublingual twice \\
\hline Quetiapine & 200 to $400 \mathrm{mg}$ twice a day \\
\hline Quetiapine XR & 400 to $800 \mathrm{mg} / \mathrm{d}$ at bedtime \\
\hline Risperidone & 1 to $6 \mathrm{mg} / \mathrm{d}$ in divided doses \\
\hline Olanzapine & 5 to $20 \mathrm{mg} / \mathrm{d}$ \\
\hline Ziprasidone & $40 \mathrm{mg}$ to $80 \mathrm{mg}$ twice a day \\
\hline
\end{tabular}

$145 \mathrm{mEq} / \mathrm{L})$. Because escitalopram can cause hyponatremia, it was discontinued in August 2019, but Mrs. $\mathrm{G}$ continued to take lurasidone, $40 \mathrm{mg} / \mathrm{d}$, divalproex, $500 \mathrm{mg} / \mathrm{d}$, and temazepam, $30 \mathrm{mg} / \mathrm{d}$.

In October and November 2020, Mrs. G's sodium level remained low at 123 and $127 \mathrm{mEq} / \mathrm{L}$. Our treatment team wondered if lurasidone could be causing Mrs. G's sodium levels to fall. Lurasidone was tapered over 3 days and discontinued. Repeat blood work showed that Mrs. G's sodium levels soon returned to normal range. In January through March 2021, her sodium levels were 138, 139, and $136 \mathrm{mEq} / \mathrm{L}$, all of which were within normal range. This confirmed our suspicion that lurasidone had caused the hyponatremia, though briefly it may have been made worse by escitalopram. Currently, Mrs. $\mathrm{G}$ is stable on

\section{Clinical Point}

Medications that can cause SIADH include antidepressants, antipsychotics, anticonvulsants, cytotoxic agents, and pain medications 


\section{Clinical Point}

\section{Patients who are prescribed psychotropics may benefit from regular monitoring of sodium levels}

Table 3

\section{Risk factors for development of hyponatremia with use of psychotropics $^{8,9}$}

\begin{tabular}{|c|}
\hline Older age \\
\hline Female sex \\
\hline History of hyponatremia \\
\hline Summer season \\
\hline Low baseline sodium level \\
\hline $\begin{array}{l}\text { Early onset, longer duration of psychiatric } \\
\text { illness }\end{array}$ \\
\hline $\begin{array}{l}\text { Comorbid medical conditions such as } \\
\text { hypertension, diabetes, hypothyroidism, } \\
\text { heart failure, head injury, stroke, liver disease, } \\
\text { malignancy }\end{array}$ \\
\hline $\begin{array}{l}\text { Concomitant use of medications such as } \\
\text { diuretics, antihypertensives, antidepressants, } \\
\text { cytochrome P450 inhibitors }\end{array}$ \\
\hline Initial phase of treatment \\
\hline
\end{tabular}

perphenazine, $4 \mathrm{mg}$ twice a day, divalproex, $500 \mathrm{mg} / \mathrm{d}$, temazepam, $30 \mathrm{mg} / \mathrm{d}$ at bedtime, and melatonin, $5 \mathrm{mg}$ at bedtime.

\section{Syndrome of inappropriate antidiuretic hormone secretion}

Syndrome of inappropriate antidiuretic hormone (SIADH) secretion can result in hyponatremia. Classes of medications that can cause SIADH include antidepressants, antipsychotics, anticonvulsants, cytotoxic agents, and pain medications. ${ }^{5}$ The class of drugs most commonly associated with SIADH is selective serotonin reuptake inhibitors, particularly citalopram. ${ }^{5}$ Among the antipsychotics, risperidone is most associated with hyponatremia. The proposed mechanism of medication-induced SIADH is an increase in the release of ADH. ${ }^{6}$ Treatment options include discontinuing the offending medication(s) or switching to a different medication.

Hyponatremia is a rare adverse effect of lurasidone, with a reported incidence $<1 \%{ }^{7}$ Although hyponatremia is potentially life-threatening, there is no recommendation to routinely monitor sodium levels in patients treated with lurasidone or other psychotropics, and patients who are prescribed lurasidone are not routinely monitored for sodium deficiency. Table $3^{8,9}$ outlines risk factors for developing hyponatremia among patients taking psychotropic medications.

Mrs. G had been taking lurasidone for a few years and experienced fluctuating sodium levels. She had been taking divalproex, which by itself could cause hyponatremia and could have added to the effects of lurasidone in lowering sodium levels. Escitalopram briefly made her hyponatremia worse. Given Mrs. G's medical illnesses, our focus had been on her underlying medical conditions rather than on a suspected medication-induced adverse effect.

In summary, patients who are prescribed lurasidone may benefit from regular monitoring of sodium levels. Monitoring sodium levels in geriatric patients who have multiple comorbid medical conditions and take multiple medications may reduce the morbidity and mortality associated with SIADH.

\section{References}

1. National Institute of Mental Health. Bipolar disorder Accessed October 12, 2021. https://www.nimh.nih.gov/ health/statistics/bipolar-disorder

2. Müller JK, Leweke FM. Bipolar disorder: clinical overview. Med Monatsschr Pharm. 2016;39(9):363-369.

3. Bobo WV, Shelton RC. Bipolar major depression in adults: Efficacy and adverse effects of second-generation antipsychotics. UpToDate. Updated September 1, 2020. Accessed October 12, 2021. https://www.uptodate.com/ contents/bipolar-major-depression-in-adults-efficacy-andadverse-effects-of-second-generation-antipsychotics

4. Epocrates. Version 21.9.1. Accessed October 14, 2021. https://www.epocrates.com

5. Shepshelovich D, Schechter A, Calvarysky B, et al. Medication-induced SIADH: distribution and characterization according to medication class. Br J Clin Pharmacol. 2017;83(8):1801-1807.

6. Guirguis E, Grace Y, Seetaram M. Management of hyponatremia: focus on psychiatric patients. US Pharm. 2013;38(11):HS3-HS6.

7. Drugs.com. Latuda side effects. Accessed October 12, 2021. https://www.drugs.com/sfx/latuda-side-effects.html

8. Ali SN, Bazzano LA. Hyponatremia in association with second-generation antipsychotics: a systematic review of case reports. Ochsner J. 2018;18(3):230-235.

9. Sahoo S, Grover S. Hyponatremia and psychotropics. J Geriatr Ment Health. 2016;3(2):108-122. 